\title{
Intravitreal Aflibercept Treatment of Anterior Segment Ischemia After Scleral Buckling Surgery
}

\author{
Muhammet Kazim Erol, Elcin Suren, Birumut Gedik \\ Department of Ophthalmology, Antalya Training and Research Hospital, University of Health Sciences, Antalya, Turkey
}

\begin{abstract}
This report describes a case of corneal edema, aqueous flare, rubeosis iridis, and neovascular glaucoma due to anterior segment ischemia after scleral buckling surgery that was treated with intravitreal aflibercept.

Anterior segment ischemia is a complication that may develop after scleral buckling surgery. The signs of anterior segment ischemia include corneal edema, aqueous flare, iris atrophy, photophobia, rubeosis iridis, neovascular glaucoma, and cataract formation. It can be diagnosed with biomicroscopy and carotid Doppler ultrasonography. In the present case, there were signs of corneal edema, aqueous flare, rubeosis iridis, and neovascular glaucoma due to anterior segment ischemia that developed after scleral buckling surgery. No pathology was found in carotid Doppler ultrasonography. Intravitreal aflibercept treatment was administered to the left eye. At a follow-up 2 weeks later, it was determined that the rubeosis iridis had receded: there were no cells in the anterior chamber, and the left eye intraocular pressure was 16 $\mathrm{mmHg}$. The patient was followed for 2 years. After I year, implantation of an Ex-press shunt (Alcon, Hunenberg, Switzerland) was performed for glaucoma. Intravitreal aflibercept treatment was administered to the left eye 4 times over 2 years. Keywords: Anterior segment ischemia, intravitreal aflibercept, neovascular glaucoma, rubeosis iridis, scleral buckling.
\end{abstract}

\section{Introduction}

Anterior segment ischemia (ASI) is a rare but important complication that can develop after posterior segment surgery. Corneal edema, aqueous flare, iris atrophy, photophobia, rubeosis iridis, neovascular glaucoma, and cataract are among the signs of ASI. Presently described is the case of a patient who developed postoperative ASI after pars plana vitrectomy and scleral buckling surgery for total retina detachment, and the treatment provided.

\section{Case Report}

A 64-year-old male patient who had no disease history presented at the clinic due to vision loss in his left eye. His eye examination indicated that his visual acuity was $10 / 10$ in the right eye, while in the left eye it was hand motion. The intraocular pressure was $15 \mathrm{mmHg}$ in the right eye and $7 \mathrm{mmHg}$ in the left eye. A fundus examination revealed total retinal detachment with a horseshoe tear in the temporal area of the left eye (Fig. I). A pars plana vitrectomy and scleral buckling surgery were performed to treat the retinal detachment. At week 2 of the postoperative follow-up, the retina was reattached and the visual acuity of his left eye was $10 / 100$ (Fig. 2). The intraocular pressure was $13 \mathrm{mmHg}$ in the right eye, and $10 \mathrm{mmHg}$ in the left eye. At postoperative month 4 , the retina remained attached, and the visual acuity of the left eye was counting fingers from I meter. The intraocular pressure was $15 \mathrm{mmHg}$ in the right eye and $9 \mathrm{mmHg}$ in the left eye. Biomicroscopy revealed edema in the cornea of the left eye and that the anterior chamber was densely populated with cells. It was thought to be anterior uveitis; therefore, topical antibiotic and topical steroid treatment was pursued. During follow-up I week later, the earlier signs persisted, the intraocular pressure of the left eye was $24 \mathrm{mmHg}$ and the

Address for correspondence: Birumut Gedik, MD. Department of Ophthalmology, Antalya Training and Research Hospital, University of Health Sciences, Antalya, Turkey

Phone: +90 2422494400 E-mail: birumut.gedik@gmail.com

Submitted Date: November 12, 2017 Accepted Date: January 15, 2018 Available Online Date: April 05, 2018

${ }^{\circ}$ Copyright 2018 by Beyoglu Eye Training and Research Hospital - Available online at www.beyoglueye.com 


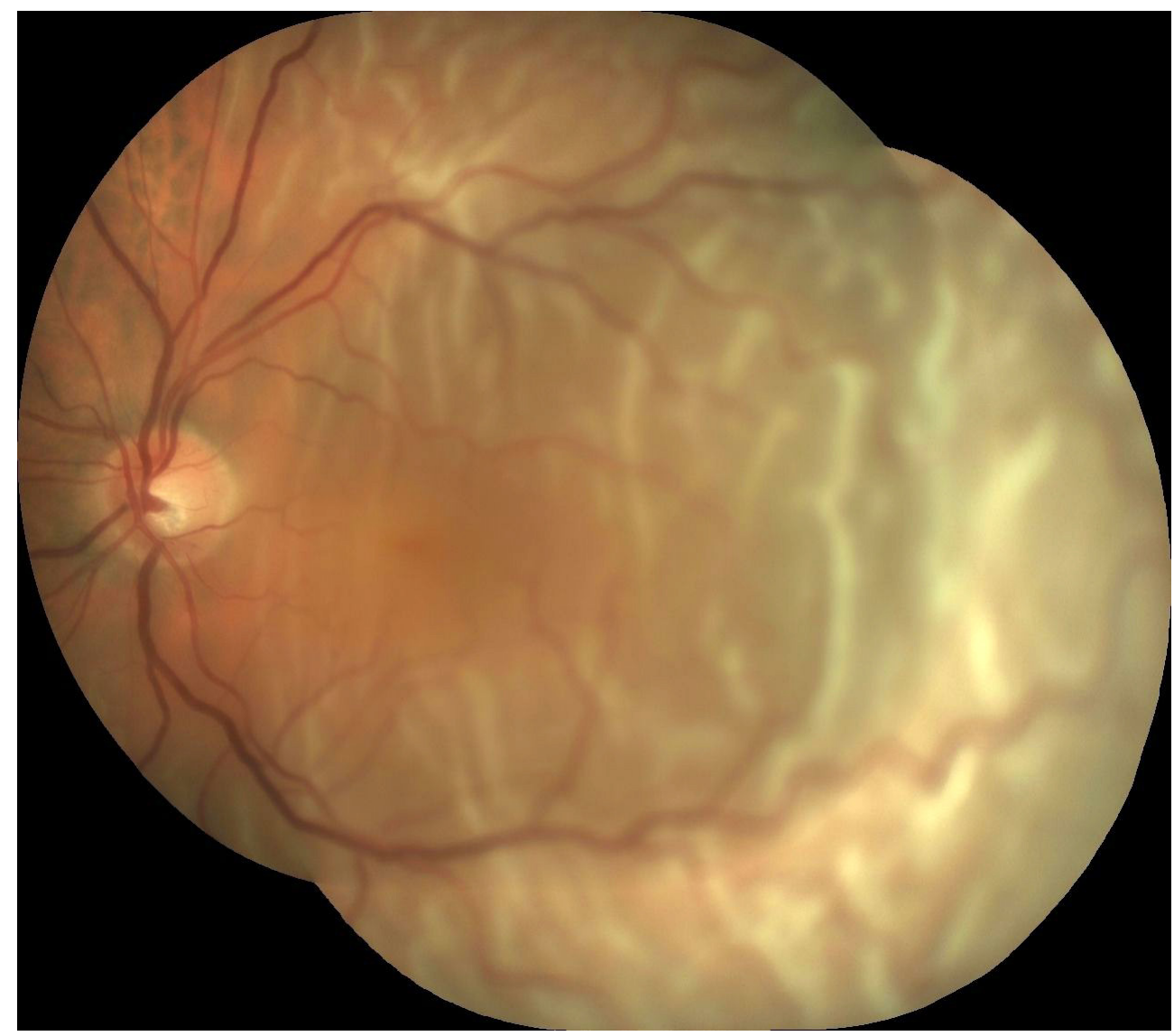

Figure I. Fundus view: Total retinal detachment in the left eye.

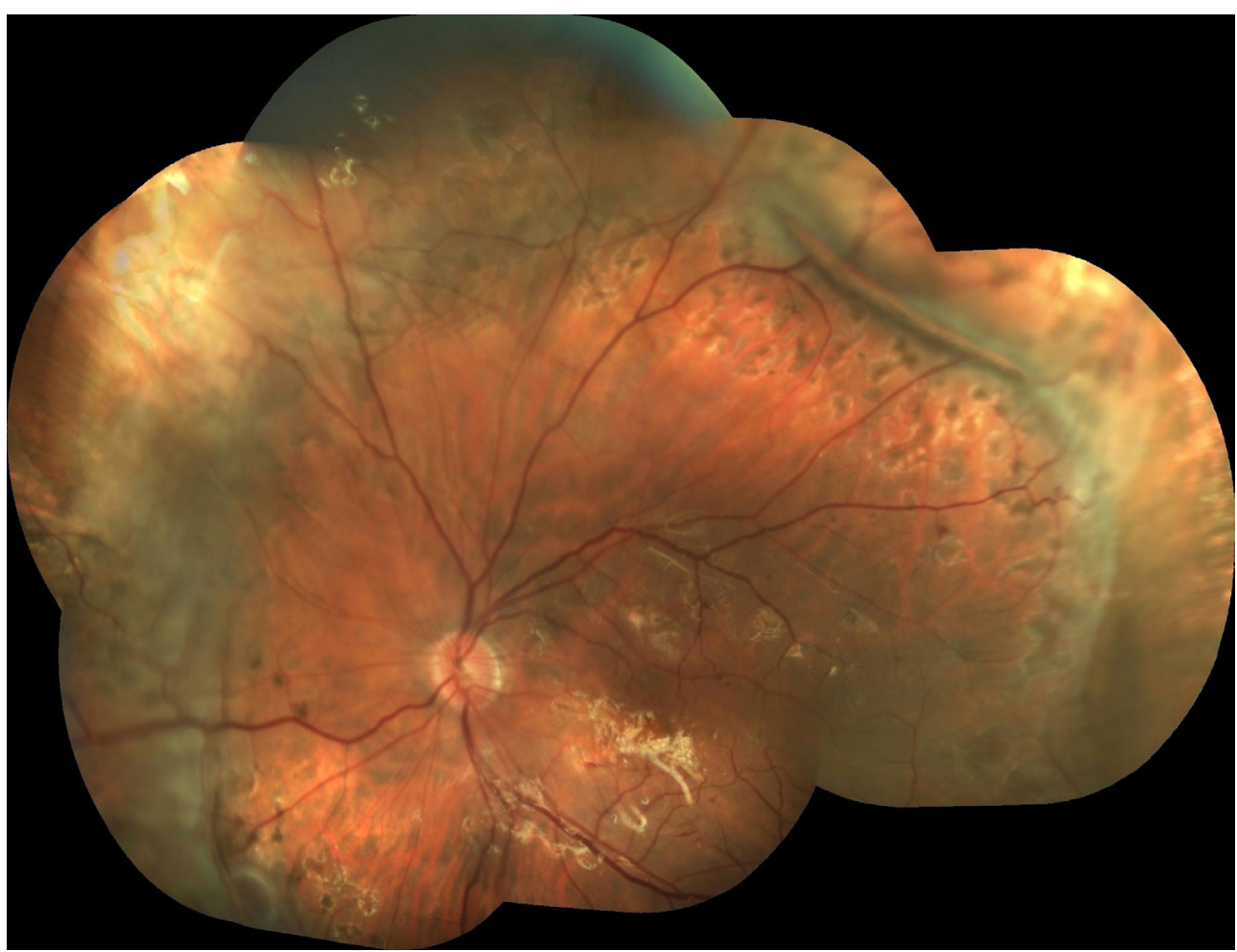

Figure 2. Fundus view: At the postoperative follow-up at week 2, the retina in the left eye was seen to be attached. 


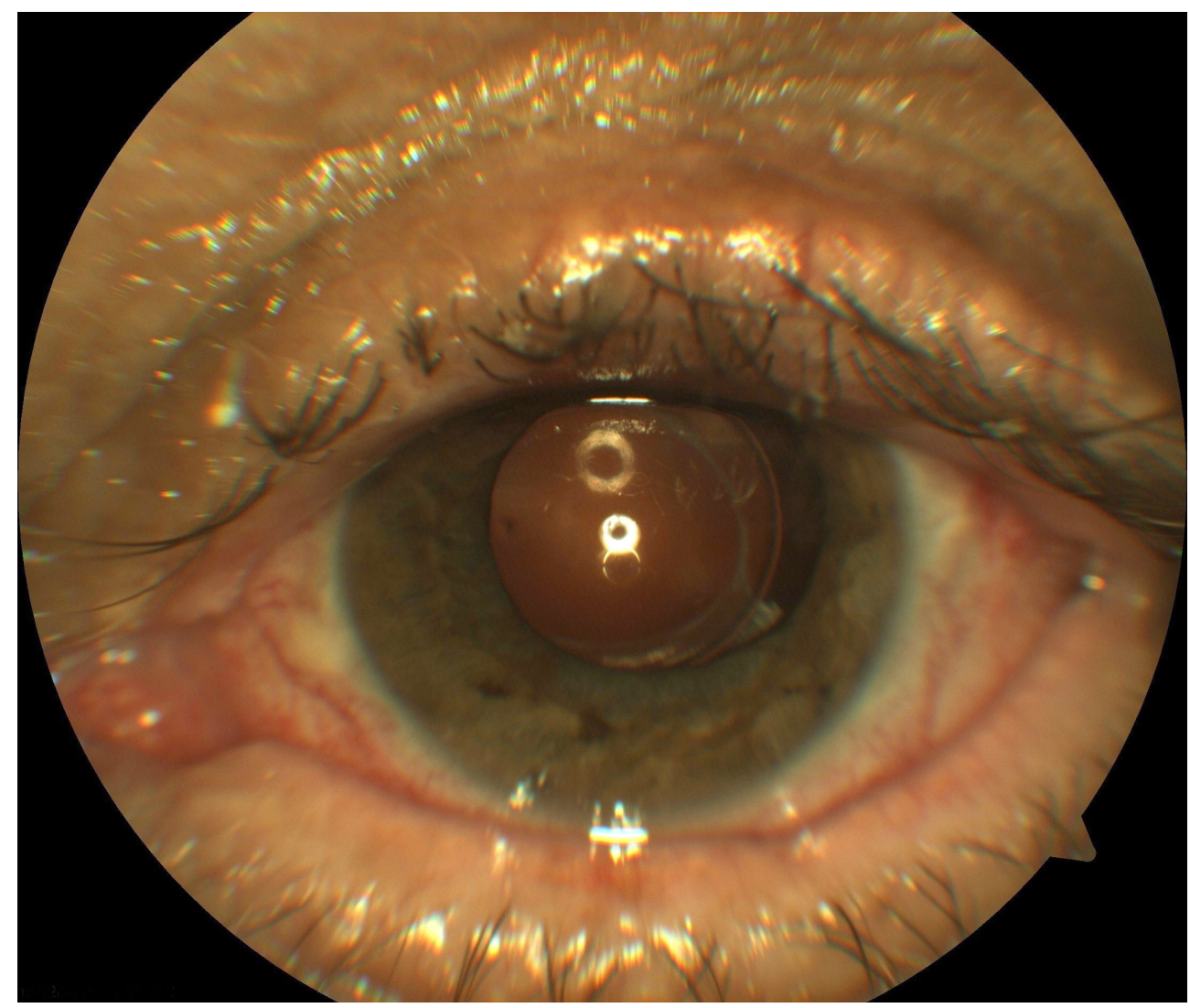

Figure 3. Anterior segment view: After 2 weeks of intravitreal injection in the left eye, the rubeosis iridis had disappeared.

left eye was also found to have rubeosis iridis. (No image was obtained because the anterior segment camera was inoperative at the time.) Anterior segment angiography was not performed. Bilateral carotid Doppler ultrasonography not reveal any pathology. There was no predisposing factor for anterior segment ischemia about surgical manoeuvres. He was diagnosed with anterior segment ischemia based on the existing signs, panretinal photocoagulation was performed and antiglaucomatous treatment was initiated. At week I follow-up, the same signs persisted and the left eye intraocular pressure was $40 \mathrm{mmHg}$. Antiglaucomatous treatment continued and intravitreal aflibercept treatment was administered to the left eye. Follow-up at week 2 revealed that the visual acuity of the left eye had increased to $3 \mathrm{mps}$. The left eye intraocular pressure was $16 \mathrm{mmHg}$. There were no cells in the anterior chamber. Rubeosis iridis had disappeared (Fig. 3). The patient was followed for 2 years. After I year, implantation of an Express shunt (Alcon, Hunenberg, Switzerland) was performed for glaucoma. Postoperative follow-up at year 2 revealed that the left eye intraocular pressure was $38 \mathrm{mmHg}$ and that the anterior chamber was densely populated with cells. The left eye was found to have rubeosis iridis (Fig. 4). Intravitreal aflibercept treatment was administered to the left eye. After 2 weeks, the left eye intraocular pressure was $17 \mathrm{mmHg}$.
There were no cells in the anterior chamber. Rubeosis iridis had resolved (Fig. 5). Intravitreal aflibercept treatment was administered to the left eye 4 times in 2 years.

\section{Discussion}

Anterior segment ischemia is a complication that may develop after posterior segment surgery. Rubeosis iridis and neovascular glaucoma are among the signs of ASI. Doi et al. (I) found ASI in $3 \%$ of 34 patients in their study exploring complications after scleral buckling surgery. The anterior segment is fed by short anterior ciliary arteries and long posterior ciliary arteries. Venous drainage occurs through the vortex veins. Anterior segment ischemia may develop due to various mechanisms, primarily as a result of hypoxia. Tanaka et al. (2) and Tawara et al. (3) demonstrated that ASI caused neovascularization in the iris in their studies on rabbits. Tanaka et al. (2) also showed that ASI led to VEGF release according to the severity of ocular ischemia. Hayreh et al. (4) reported that ASI developed after scleral buckling surgery due to venous congestion caused by compression of the vortex veins. Another study showed that ASI developed after scleral buckling surgery due to intervention in the long posterior ciliary arteries (5). Furthermore, another study on rabbits demonstrated that scleral buckling surgery 


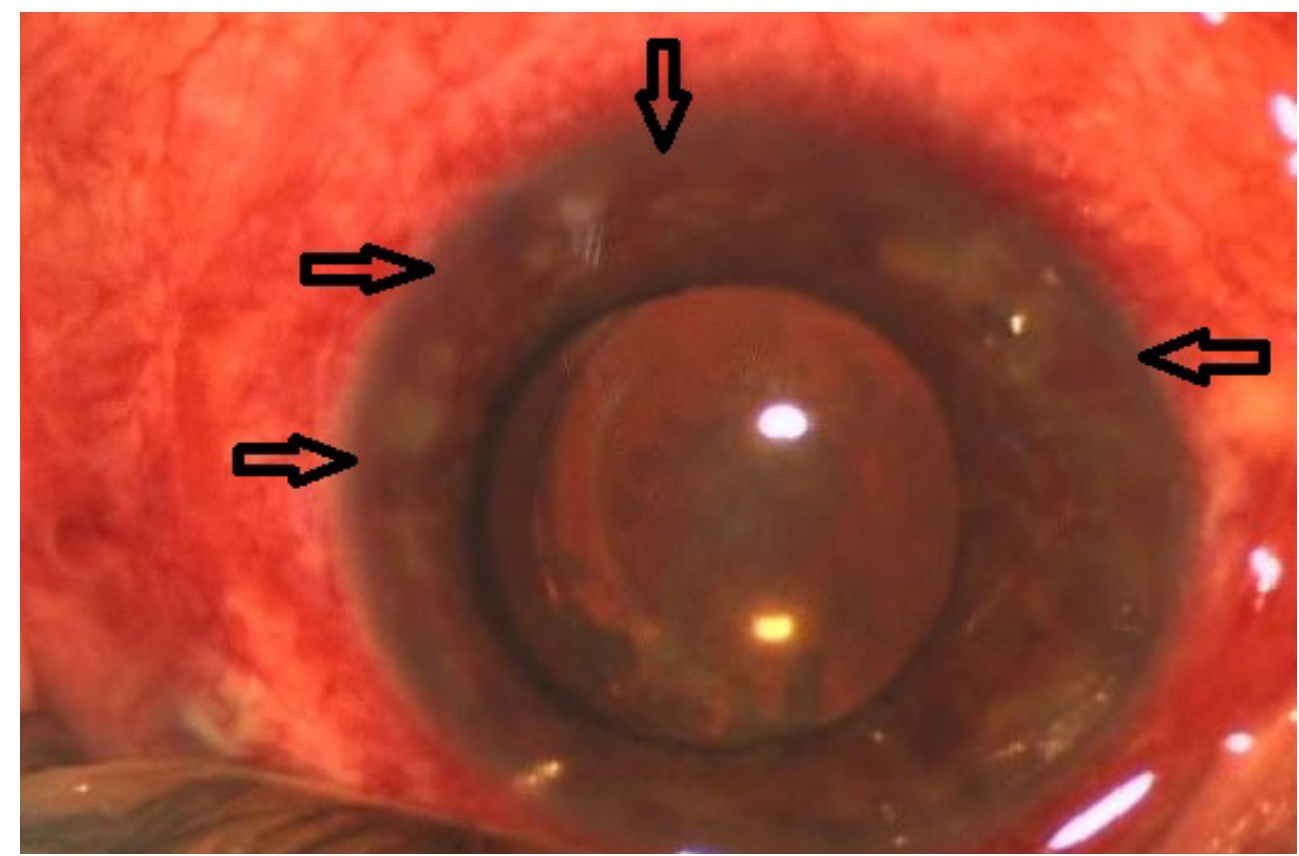

Figure 4. Anterior segment view: Postoperative follow-up at year 2 revealed rubeosis iridis (arrows) in the left eye.

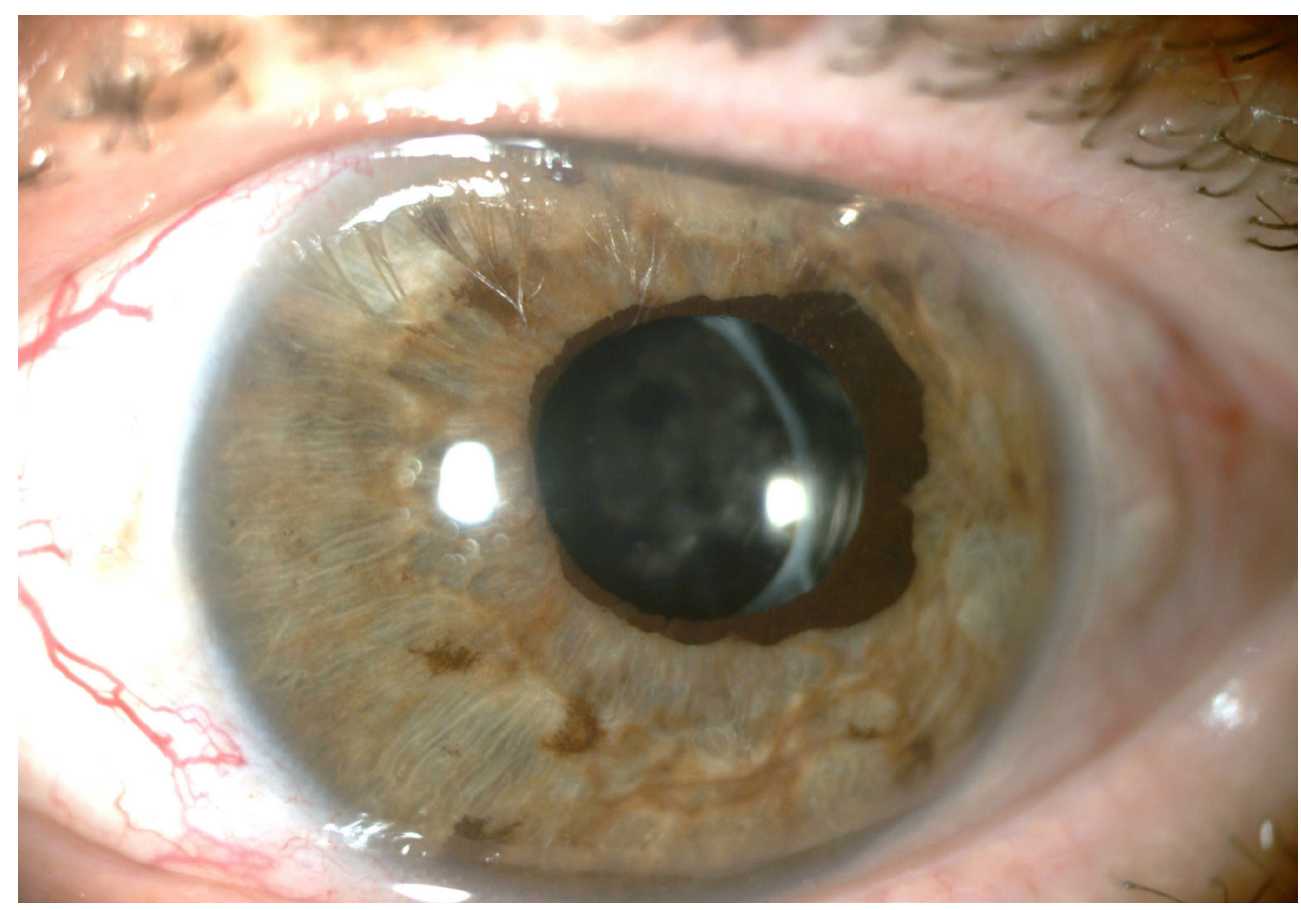

Figure 5. Anterior segment view: After 2 weeks of intravitreal injection to the left eye, the rubeosis iridis disappeared.

decreased perfusion in the iris and ciliary body (6).

The signs of ASI include corneal edema, aqueous flare, iris atrophy, photophobia, rubeosis iridis, neovascular glaucoma, and cataract formation. In our case, corneal edema, rubeosis iridis, and neovascular glaucoma were present at the postoperative fourth month. Aqueous flare and cornea edema are also symptoms of anterior uveitis (7). Therefore,
ASI should also be considered for patients who have the preliminary diagnosis of uveitis.

Biomicroscopy and carotid Doppler ultrasonography are useful in the diagnosis of patients with anterior segment ischemia (7). The biomicroscopy results revealed corneal edema, dense cell population in the anterior chamber, and rubeosis iridis. Carotid Doppler ultrasonography did not re- 
veal any pathology.

Treatment options for patients who develop rubeosis iridis and neovascular glaucoma include antiglaucomatous medications (8), panretinal photocoagulation $(9,10)$, antiglaucomatous surgery (II), and intravitreal injection (I2-I4). In their case report, Janssens et al. (12) reported that they injected intravitreal Bevacizumab into a patient who had developed rubeosis iridis and neovascular glaucoma due to ASI after scleral buckling surgery and 2 months after the injection, rubeosis iridis remained in only a small area. Hung et al. (I3) stated in their case report that they administered an intravitreal Bevacizumab injection for rubeosis iridis and it regressed 6 days later (I3). Durmaz et al. (14) reported that rubeosis iridis regressed after intravitreal aflibercept and triamcinolone acetonide treatment they administered to a patient who developed rubeosis iridis (14). We applied intravitreal aflibercept treatment in a patient who developed rubeosis iridis and neovascular glaucoma due to ASI after scleral buckling surgery and we found that the rubeosis iridis disappeared. There were no cells in the anterior chamber and intraocular pressure was normal 2 weeks later.

\section{Conclusion}

This case report is a description of a patient who developed corneal edema, rubeosis iridis, and neovascular glaucoma due to ASI that developed after pars plana vitrectomy and scleral buckling surgery. The patient was treated with intravitreal aflibercept and we found that the rubeosis iridis resolved: there were no cells in the anterior chamber and intraocular pressure was normal 2 weeks later. Intravitreal aflibercept is a fast and effective agent in the treatment of neovascularization due to hypoperfusion in ASI. It should be remembered that ASI may developed in a patient who presents with corneal edema, rubeosis iridis, and high intraocular pressure after scleral buckling surgery, while keeping in mind also that some symptoms of $\mathrm{ASI}$, such as aqueous flare and corneal edema, overlap with those of anterior uveitis.

\section{Disclosures}

Informed consent: Written informed consent was obtained from the patient for the publication of the case report and the accompanying images.

Peer-review: Externally peer-reviewed.

Conflict of Interest: None declared.

Authorship Contributions: Involved in design and conduct of the study (MKE, ES, BG); preparation and review of the study (MKE, ES, BG); data collection (MKE, ES, BG).

\section{References}

I. Doi N, Uemura A, Nakao K. Complications associated with vortex vein damage in scleral buckling surgery for rhegmatogenous retinal detachment. Jpn J Ophthalmol 1999;43:232-8.

2. Tanaka T, Matsuo T, Ohtsuki H. Aqueous vascular endothelial growth factor increases in anterior segment ischemia in rabbits. Jpn J Ophthalmol 1998;42:85-9. [CrossRef]

3. Tawara A, Kubota T, Hata Y, Sakamoto T, Honda M, Yoshikawa $\mathrm{H}$, et al. Neovascularization in the anterior segment of the rabbit eye by experimental anterior ischemia. Graefes Arch Clin Exp Ophthalmol 2002;240:144-53. [CrossRef]

4. Hayreh SS, Baines JA. Occlusion of the vortex veins. An experimental study. Br J Ophthalmol 1973;57:217-38. [CrossRef]

5. Lee JP, Olver JM. Anterior segment ischaemia. Eye (Lond) 1990;4:1-6. [CrossRef]

6. Bakri SJ, Snyder MR, Reid JM, Pulido JS, Singh RJ. Pharmacokinetics of intravitreal bevacizumab (Avastin). Ophthalmology 2007; | | 4:855-9. [CrossRef]

7. Sivakumar RR, Rao NA. Anterior Segment Ischemia in Viper Bite. Ocul Immunol Inflamm 2016;24:49-54.

8. Mendrinos E, Machinis TG, Pournaras CJ. Ocular ischemic syndrome. Surv Ophthalmol 2010;55:2-34. [CrossRef]

9. Johnston ME, Gonder JR, Canny CL. Successful treatment of the ocular ischemic syndrome with panretinal photocoagulation and cerebrovascular surgery. Can J Ophthalmol 1988;23:I I4-9.

10. Chen KJ, Chen SN, Kao LY, Ho CL, Chen TL, Lai CC, et al. Ocular ischemic syndrome. Chang Gung Med J 200I;24:483-9I.

I I. Sivak-Callcott JA, O'Day DM, Gass JD, Tsai JC. Evidence-based recommendations for the diagnosis and treatment of neovascular glaucoma. Ophthalmology 2001;108:1767-76. [CrossRef]

I2. Janssens K, Zeyen T, Van Calster J. Anterior segment ischemia with rubeosis iridis after a circular buckling operation treated successfully with an intravitreal bevacizumab injection: a case report and review of the literature. Bull Soc Belge Ophtalmol 2012:5-9.

13. Hung JH, Chang YS. Ocular ischemic syndrome. CMA 20।7; |89:E804. [CrossRef]

14. Durmaz Engin C, Ayhan Z, Men S, Yaman A, Saatci AO. Bilateral Severe Sterile Inflammation with Hypopyon after Simultaneous Intravitreal Triamcinolone Acetonide and Aflibercept Injection in a Patient with Bilateral Marked Rubeosis Associated with Ocular Ischemic Syndrome. Case Rep Ophthalmol Med 20 I7;20 I7:5 I 23963. [CrossRef] 